\title{
The Relationship between Human Resource Information System (HRIS) Functions and Human Resource Management (HRM) Functionalities
}

\author{
Bader Yousef Obeidat \\ Assistant Professor of Strategic Management \\ Department of Business Management Faculty of Business, University of Jordan \\ Amman, Jordan
}

\begin{abstract}
Received: August 17, $2012 \quad$ Accepted: September 4, 2012 Published: October 1, 2012
doi:10.5296/jmr.v4i4.2262 URL: http://dx.doi.org/10.5296/jmr.v4i4.2262
\end{abstract}

\begin{abstract}
The purpose of this paper is to discuss the relationship between Human Resource Information System (HRIS) functions and Human Resource Management (HRM) functionalities. The theoretical framework of this paper is based on previous HRM and HRIS research where the contributing role of HRIS is measured by the compliance and application level of HRIS functions to HR functionalities. A survey questionnaire was sent to five different banks and a response rate of $61.5 \%$ was received. The target groups of the questionnaire were HR departments that include HR managers and professionals in the Jordanian banking sector.

In this study, human resource information system functions were found to have a relationship with HRM functionalities. More specifically, it was found that strategic integration, forecasting and planning, human resources analysis, and communication and integration have no relationship with human resource functionalities. Whereas, it was found that performance development, knowledge management, and records and compliance as dimensions of human resources information systems have a relationship with human resources functionalities.
\end{abstract}

Keywords: Human Resource Management, HRM functionalities, Human Resource Information System. 


\section{Introduction}

In today's knowledge-economy, organizational success depends tremendously on the performance of human resource management (HRM) (Lippert and Swiercz, 2005; Troshani et al., 2011). Furthermore, Human Resource Management (HRM) has recently turned its concentration on knowledge sharing and strategic workforce analysis and has been increasingly evolving into a significant contributor on the organizational strategic management (Rodriguez and Ventura, 2003; Troshani et al., 2011).

This turn in HRM practices is partially attributed to technologies enablers, such as human resource information system (HRIS) which consists of systematic procedures and functions to acquire, store, retrieve, analyze, manipulate, and disseminate relevant information concerning organizational HR (Lippert and Swiercz, 2005; Troshani et al., 2011).

To increase the effectiveness of HRM, organizations are becoming more and more dependent on HRIS (Ball, 2001; Lippert and Swiercz, 2005; Troshani, et al., 2011). At the functional level, HRIS can keep track of employees', applicants', and contingent workers' qualifications, demographics, performance evaluation, professional development, payroll, recruitment, and retention (Harris and Desimone, 1995; Troshani et al., 2011).

With HRIS, the administrative efficiency maintains faster information processing, improved employee communications, and greater information accuracy (Overman, 1992; Beadless, et al., 2005), lower HR costs and overall HR productivity improvements (Beadles et al., 2005; Dery et al., 2009; Wiblen et al., 2010; Troshani et al., 2011).

Strategic value can be derived using HRIS tools that assist decision-making concerning vital HR functions (Farndale et al., 2010; Troshani et al., 2011). For example, an HRIS can be considered as a tool that provides strategic planners with the needed information enabling them to forecast future workforce demand and supply requirements. Moreover, it can be considered as a tool that helps employers in retaining the right employees. This can be done by paying them competitive salaries compared to the market, and training them to develop their skills and abilities to carry out their existing and future jobs.

\section{Literature Review}

\subsection{Human Resource Management (HRM)}

In today's knowledge economy, the success of organizations depends mainly on the performance of their human resources (HR) (Lippert and Swiercz, 2005). Human resource management is about the procedures and practices that encompass the human resource aspect within organizations (Dessler and Al Ariss, 2012). Such practices should be connected to the overall strategy of the organization. This was discussed by Bratton and Gold (2003) who stated that "the strategic approach to managing employment relations which emphasizes that leveraging people's capabilities is critical to achieving sustainable competitive advantage" ( $p$. 7). Many researchers supported this and commented that the change from a primarily administrative personnel function to a more strategic position attends to re-design the nature of the HRM functions (see for example Ulrich, 1997; Sheehan and Cooper, 2011). 
The functions re-design is estimated to provide HRM with a better opportunity of impact on strategic decisions in order to eventually improve organizational performance (Bowen and Ostroff, 2004; Sheehan and Cooper, 2011). Such functions are planning, recruitment, selection, appraisal and performance management, reward management, development, employee relations, health and safety, and union- management relations (DeCenzo and Robbins, 2010). Furthermore, Akhtar and his associates (2008) added that training, participation, result-oriented appraisals and internal career opportunities considered a valid human resource management (HRM) practices.

As mentioned above, many researchers have discussed the issue of HRM and its functionalities. For example, Martinsons (1997) and Beulen, (2009) investigated the issue of HRM functionalities and commented that distinguishing these functionalities arises from the perspective of organizational and employee-centric view. They added that the strategic dimension for organizational continuity and prosperity relies immensely on value and importance of the human capital which identifies the knowledge as a significant part of this capital. These functions are human resource planning, staff development and regulatory compliance, benefits administration, performance appraisal, and recruitment and selection.

Human Resource Planning: the process of making a decision about what positions inside the firm to fill and how to fill them (Desseler and Al Ariss, 2012). It is also the process of identifying current and future HR needs for an organization to achieve its goals as well as forecasting a firm's future demand and supply (DeCenzo and Robbins, 2010). This function serves as a link to the overall strategic plan of an organization. Human resource planning is a continuous process that works on both long-term and short term.

Staff development: Development of existing staff needs to be maintained as different industries and sectors continue to implement new technologies. Supporting employees in identifying their professional development options and targets is the purpose of education and training tools (Beulen, 2009). As such, it contributes radically to retention management. HRIS can be used in a staff development and facilitating employees identification and enrollment of adequate or required training courses that are related to their current job or to develop their skills and abilities that enable them to carry out new jobs (Martinsons, 1997; Beulen, 2009).

Benefits Administration: Benefits administration is considered an important function for human resource management, since; it is part of retention management and can be used to motivate employees. It involves the creation and management of employee benefits, as well as providing means for employees to be trained in understanding how the benefits work (Dessler, 2013). It also involves what types of standards employees must meet in order to qualify for the benefits (Dessler, 2013; Dessler and Al Ariss, 2012).

Performance Appraisal: Performance appraisals are used for administrating remunerations and salaries, and identifying individual employee strengths and weaknesses (Mathis and Jackson, 2010). It is variously called employee rating, employee evaluation, performance review, or result appraisal. It is used to assess an employee's performance and provide feedback about past, current, and future performance expectations (Beulen, 2009). 
Recruitment and Selection: Gatewood and his colleagues (2008) defined HR selection as "... the process of collecting and evaluating information about an individual in order to extend an offer of employment" (p. 3). They added that this process "is performed under legal and environmental constraints and addresses the future interest of the organization and of the individual" (p. 3). Mathis and Jackson (2010) summarized this and commented that the selection process is concerned with choosing qualified persons to fill those jobs.

The aim of recruitment is to provide a satisfactory pool of qualified individuals to fill jobs in a firm (DeCenzo and Robbins, 2010). Employees, job design, and job analysis set the foundation for recruitment by identifying what various people do in their jobs and how they are affected by them. Through HR planning, managers anticipate the current and future demand of employees and the nature of workers issues, including the retention of employees. These factors are used when recruiting applicants for job opening.

\subsection{Human Resource Information Systems (HRIS)}

The use of technology in HR has expanded spectacularly and is continuing to change HR management activities with executives, managers, and employees (Mathis and Jackson, 2010). HRIS has grown in popularity since the 1960s (Lederer, 1984). A survey conducted in a study carried out by Ball (2001) showed that 60 percent of Fortune 500 companies during late 90's use the HRIS to support daily human resource management (HRM) operations. HRIS is now used not only for administrative purposes but also for strategic and business decision-making purposes (Broderick and Boudreau, 1992; Kossek et al., 1994; Kovach et al., 2002).

When the HRIS function was computerized, fast decision making was able to take place in the development, planning, and administration of HR because data became much easier to store, retrieve, update, classify, and analyze. In addition, an HRIS can strengthen an organization's character in general (Sadri and Chatterjee, 2003).

Tracking information concerning an applicant's or an employee's qualifications and demographics, recruitment, professional development, performance evaluation, payroll, retention, and attrition are essential for success at the HR functional level (Harris and Desimone, 1995). This was supported by many researchers who commented that in order to increase the effectiveness of HRM, organizations are becoming increasingly reliant on HRIS (see for example Lippert and Swiercz, 2005; Ball, 2001; Troshani et al., 2011). Accordingly, by facilitating improved access to metrics, HRIS can improve administrative efficiency through faster information processing, improved employee communications, greater information accuracy, lower HR costs and overall HR productivity improvements (Beadles et al., 2005; Dery et al., 2009; Wiblen et al., 2010; Troshani et al., 2011).

Furthermore, more and more companies use an HRIS to actively support both their HR management and their business management (Shrivastava and Shaw, 2004; Hussain et al., 2007; Lepak et al., 2006; Beulen, 2009). An HRIS can be defined as "a composite of database, computer applications, hardware and software necessary to collect/record, store, manage, deliver, present, and manipulate data for human resource" (Broderick and Boudreau, 1992). 


\section{Macrothink Institute ${ }^{\mathrm{TM}}$}

HRIS differs in its functionality and application from administrative applications, talent management applications, workforce management applications, service delivery applications and workforce analysis and/or decision support applications. This means a shift has been made from labor-intensive HRM to technology-intensive HRM (Florkowshi and Olivas-Lujan, 2006; Beulen, 2009). The transformation has not been trivial, Kovach et al. (2002, p.46) considered "getting the staff to adapt and adapt to a new system, which is actually a new business process for them" to be the most important difficulty. Many studies came out with many functions that represent an HRIS. For example, HRIS functions include corporate communication, recruitment, selection, training, employee opinion survey, compensation, payroll services and employee verification as well as general staff related information and demographics (Ngai and Wat, 2006; Beulen, 2009; Holincheck et al.,2007). However, Mayfield and his associates (2003) added that the functions of HRIS comply with organizational interests in maintaining and managing the human capital based on the organizational vision and the strategy of achieving that vision. It supports and integrates various aspects in relation to organizational sustainability. In their study, Mayfield and his colleagues identified seven main component of an HRIS model. They commented that those components are considered to be the primary components of this model which form a comprehensive framework of an HRIS. They stated that "more specifically, our model addresses all major HRIS components and offers information on how these facets interact to support each other and larger organizational outcome" (P. 139). These components (functions) are portrayed in figure 1.

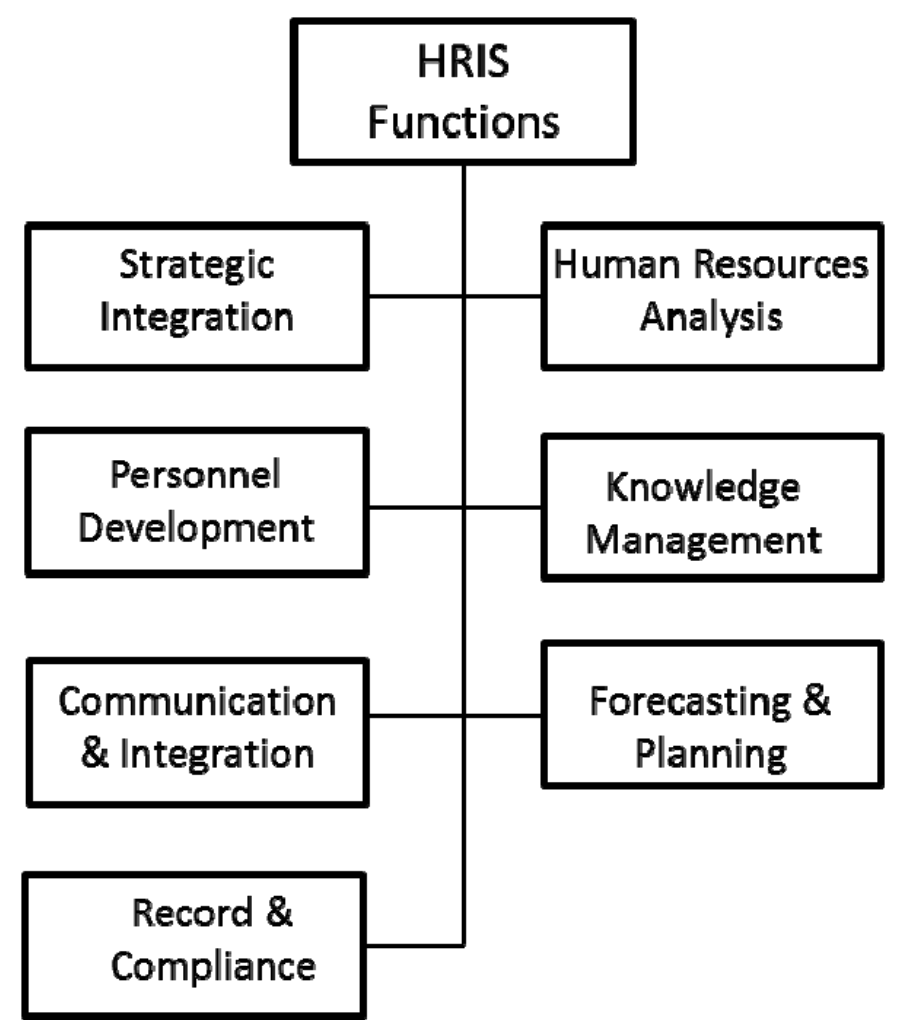

Figure 1. HRIS Functions 
Casico (2006) adopted this framework; however, he divided the seven functions into two dimensions. He commented that four functionalities for HRIS are related to HR practices concerned directly with the organizational employees. These functions are personnel development, communication and integration, records and compliance and HR Analysis. He added that the three remaining functionalities (strategic integration, forecasting and planning and knowledge management) represent HR department role in the organizational practices in general and the strategic management in specific.

Strategic Integration: HRIS leads to an improvement in organizational performance and changes the method in which organizations are managed (Ordonez de pablos, 2004; Katou and Budhwar, 2006; Troshani et al., 2011). HRIS facilitates strategic value generation by helping design and implement internally consistent policies and practices which ensure the human resources contribute to accomplishing business objectives (Boateng, 2007; Troshani et al., 2011). Strategic value can be derived by HRIS tools that assist with decision-making regarding essential HR functions (Farndale et al., 2010; Troshani et al., 2011).

Human Resources Analysis: Most of the HR decisions are based on this function. Using this function, an organization makes a decision of whether their personnel capabilities are congruent or not. Human resource analysis is considered to be an ongoing mean of collecting and identifying human resource needs (Mayfield, et al., 2003).

Personnel Development: In this function, an organization can decide on any deficiency an employee has, accordingly, make a decision of the most appropriate training and/or development method to use to overcome that deficiency (Dessler, 2013). Such a deficiency can be determined using an individual employee performance, appraisal, and career development which all can be accomplished through an HRIS (Lippert and Swiercz, 2005).

Knowledge Management: HRIS are mostly created for knowledge management of HRM. The reason for having an HRIS is the need to control the basic data on personnel, which constructs organizations more profitable and effective. These concerns are element of the big challenge linked to HRIS development, one of which is also the abilities to design and implement HRIS (Remenyi, 2005). Furthermore, HRIS makes vital contributions to knowledge management by advancing organizational learning. For example, HRIS facilitates double loop learning feedback that enables organizational change and discussion, intra organizational communication and decision-making, and shared visions (Argryis and Schon, 1996; Mayfield, et al., 2003).

Communication and Integration: Inter-organizational communication supports and coordinates different organizational activities as well as changes (Mayfield, et al., 2003; Casico, 2006). In this function, an appropriate HRIS involves a communication mechanism suitable for communicating necessary information to all customers within and outside an organization (Mayfield, et al., 2003).

Forecasting and Planning: This function is used to transform the input of an HRIS analysis into its predictive feedback about organizational future personnel and skill needs (Mayfield, et al., 2003). Data maintained in an HRIS can be used as a competitive information resource 
for practically all management functions including planning, organizing, monitoring, controlling and leading. HRIS technology supports strategic planning through the creation of work force supply and demand needs, requirements and forecasting (Lippert and Swiercz, 2005).

Records and Compliance: The records and compliance function is important to meet both various legal requirements that mandate specific information retention, and to present a database that puts in to the proper functioning of the other HRIS functions. Records and compliance function provides very important data for knowledge management (Mayfield, et al., 2003).

\section{Research Framework}

The development of technologies has enabled organizations to facilitate performing its tasks and obtain a better market advantage by simplifying handling and integrating different organizational processes and revealing alternative options for conducting business. Among these advances in technology is the use of information systems in different departments of organizations. One of the major information systems in any large organization and medium organizations is HRIS.

In order to study the relation between HRIS functions and HRM functionalities, a frame was built in which HRIS functions were dealt with as independent variables, whereas HRM functionalities were dealt with as dependent variables. HRIS consists of seven functions as introduced by Mayfield and his associates (2003) and adopted by Casico (2006) namely, strategic integration, forecasting and planning, performance development, human resources analysis, knowledge management, communication and integration, and records and compliance.

Similarly, HRM is divided into five functionalities which have been discussed by most of human resources scholars. However, for the purpose of this study, the model which was proposed by Martinsons (1997) and Beulen, (2009) will be adopted. Martinsons and Beulen dealt with HRM functions as applications of knowledge-based systems which includes human resource planning, staff development and regulatory compliance, benefits administration, performance appraisal, and recruitment and selection. Figure 2 depicts the research framework and the elements to be investigated. 


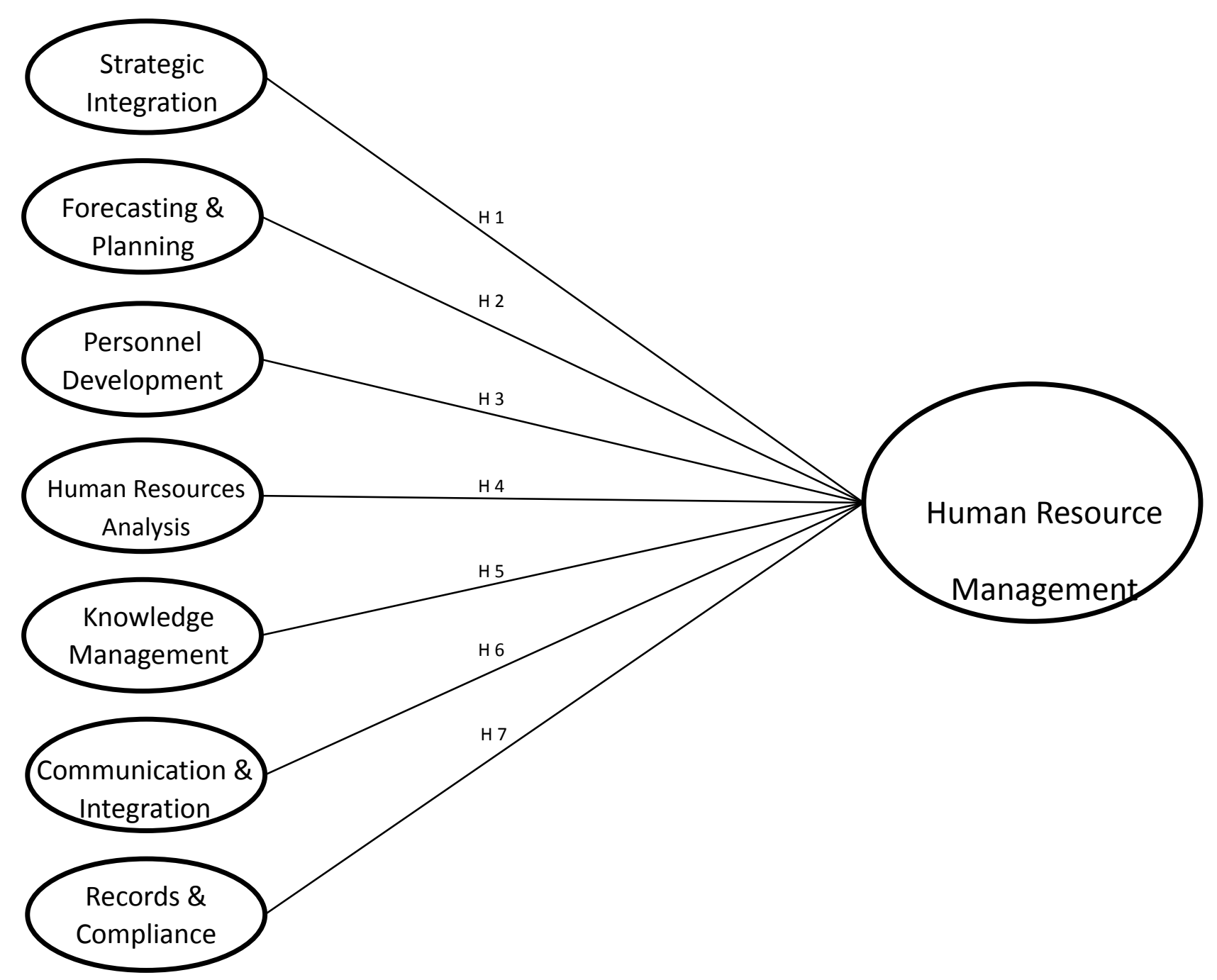

Figure 2. Research Framework

The main goal of this study is to investigate the relationship between HRIS functions and HRM functionalities. This is done with a purpose of examining the importance of HRIS in organizations and the role it plays in maintaining sustainability, growth, expansion or development of different organizations in general and for the banking sector in specific. Accordingly, this study tries to answer the following main hypothesis:

There is a significant relationship between human resource information systems functions and human resource management functionalities

For this, the following hypotheses will be tested:

H1: There is a significant relationship between strategic integration and human resource management functionalities 
$\mathrm{H} 2$ : There is a significant relationship between forecasting and planning and human resource management functionalities

H3: There is a significant relationship between personnel development and human resource management functionalities

H4: There is a significant relationship between human resources analysis and human resource management functionalities

H5: There is a significant relationship between knowledge management and human resource management functionalities

H6: There is a significant relationship between communication and integration and human resource management functionalities

H7: There is a significant relationship between record and compliance and human resource management functionalities

\section{Methodology}

In order to address the research objective, data was gathered using a structured questionnaire, which enables the hypotheses testing. Fifty six questions were included in this questionnaire which attempts to measure the several dimensions that represent both HRIS function and HRM functionalities. The population of the study consisted of all commercial banks trading in the Jordanian banking sector with a total number of fifteen banks, the population was limited to HR departments in each bank's headquarter in the capital of Jordan (Amman).

A copy of a letter asking for a permission of access was sent to the fifteen banks in Jordan, however due to privacy issues, only five banks approved the data collection process. Therefore, it can be argued that the five banks played a main role in selecting themselves to be included in this research rather than the researcher himself. These five banks represent $33.3 \%$ of the population. 200 questionnaires were distributed randomly to HR professionals in these banks while ensuring that all HR managers in the respected departments were included. Only 123 questionnaires were returned from these five banks with a response rate of $61.5 \%$. The study carried out by Mayfield and his colleagues in 2003 was used to build the factors that are used to measure HRIS. Whereas, the studies carried out by Martinsons (1997) and Beulen, (2009) were used to build the factors that are used to measure HRM.

\section{Data Analysis and Results}

In order to examine the research hypotheses, the data collected through the questionnaire, distributed to the HR professionals in five banks in Jordan were analyzed using Statistical Package for Social Sciences (SPSS) version 17.

\section{Profile of the Respondents}

The respondents of this study were asked to give information about their gender, age, educational level, and family status. From the results appear in Table 1 below, the number of male respondents is more than the number of female ones. However the difference is not that 
great as male respondents represent 52.8 of the sample whereas females represent 47.2 of the sample. This indicates that this factor has a minimal effect on the results of this study. Furthermore, married respondents represent 50.4 of the sample whereas the unmarried ones represent 49.6 of the whole sample. This also indicates that this factor has a minimal effect on the results of this study.

Table 1. Respondents’ Demographic Profile

\begin{tabular}{|l|l|l|}
\hline & Frequency & Percent \\
\hline Gender & 65 & 52.8 \\
\hline Male & 58 & 47.2 \\
\hline Female & 27 & 21.95 \\
\hline Age & 56 & 45.53 \\
\hline $18-24$ & 19 & 15.44 \\
$25-34$ & 17 & 13.83 \\
$35-44$ & 4 & 3.25 \\
$45-54$ & \multicolumn{2}{|c|}{} \\
55 and Above & 7 & 5.6 \\
\hline Educational Level & 16 & 13 \\
\hline Below High School & 4 & 3.3 \\
High School & 88 & 71.6 \\
Diploma & 8 & 6.5 \\
Bachelor Degree & \multicolumn{2}{|c|}{} \\
\hline Graduate Studies & 62 & 50.4 \\
\hline Marital Status & 61 & 49.6 \\
\hline Married & & \\
\hline Single & & \\
\hline
\end{tabular}

\section{Reliability Testing (Cronbach Alpha)}

In this study, scale reliability was assessed using Cronbach's alpha coefficient. Table 2 below presents the Cronbach's alpha coefficients for the different dimension and variables of the questionnaire. Indeed, it can be seen that the results range from 0.740 to 0.948 . Therefore, all values exceed the recommended threshold 0.70 , indicating good internal consistency among the items within each dimension, each variable, and the entire scale. 
Table 2. Cronbach Alpha coefficients

\begin{tabular}{|l|c|c|}
\hline & Cronbach alpha & No. of items \\
\hline Human Resource Information Systems & 0.966 & 30 \\
\hline Strategic Integration & 0.740 & 4 \\
\hline Forecasting \& Planning & 0.905 & 4 \\
\hline Performance Development & 0.846 & 7 \\
\hline Human Resources Analysis & 0.862 & 3 \\
\hline Knowledge Management & 0.782 & 4 \\
\hline
\end{tabular}

\section{Hypothesis Testing}

Before testing the hypotheses, multicollinearity diagnosis was done using Variance Inflation Factor (VIF) and tolerance value. The tolerance of an independent variable, which is an additional method to measure the effects of multicollinearity, ranges from zero to one. A VIF value of 5 or 10 and above and a tolerance of less than 0.20 indicate that variables are multicollinear (Chadha and Kapoor, 2009).

Table 3. Multicolinearity test

\begin{tabular}{|l|l|l|}
\hline & Tolerance & VIF \\
\hline Strategic Integration & 0.313 & 3.190 \\
\hline Forecasting \& Planning & 0.239 & 4.175 \\
\hline Performance Development & 0.291 & 3.435 \\
\hline Human Resources Analysis & 0.215 & 4.669 \\
\hline Knowledge Management & 0.233 & 4.283 \\
\hline Communication \& Integration & 0.244 & 4.101 \\
\hline Records \& Compliance & 0.226 & 4.431 \\
\hline
\end{tabular}

As shown in Table 3 above, it can be seen that VIF range between 3.190 and 4.669 values which are well-below five. On the other hand, the tolerance values range between 0.215 and 0.313 which are above 0.2. These factors indicate that there is no evidence of multicollinearity problem in the regression model. In addition to the VIF and tolerance values, a Correlation Matrix was computed the independent variable dimensions to check correlation between them as shown in Table 4. According to Sekaran and Bougie (2010), a value of 0.75 and above suggests high correlation between the variables. The results in the above table, are all below 0.75 and thus do not suggest high correlation between the variables. Therefore, these findings also show that there is no evidence of multicollinearity problem. 


\section{Ml Macrothink}

Table 4. Correlations between Constructs

\begin{tabular}{|l|l|l|l|l|l|l|l|}
\hline Constructs & SI & FP & PD & HA & KM & CI & RC \\
\hline $\begin{array}{l}\text { Strategic } \\
\text { Integration (SI) }\end{array}$ & 1.000 & & & & & & \\
\hline $\begin{array}{l}\text { Forecasting and } \\
\text { Planning (FP) }\end{array}$ & 0.747 & 1.000 & & & & & \\
\hline $\begin{array}{l}\text { Performance } \\
\text { Development (PD) }\end{array}$ & 0.681 & 0.667 & 1.000 & & & & \\
\hline $\begin{array}{l}\text { Human Resources } \\
\text { Analysis (HA) }\end{array}$ & 0.775 & 0.790 & 0.580 & 1.000 & & & \\
\hline $\begin{array}{l}\text { Knowledge } \\
\text { Management (KM) }\end{array}$ & 0.708 & 0.650 & 0.589 & 0.655 & 1.000 & & 1.000 \\
\hline $\begin{array}{l}\text { Communication } \\
\text { and Integration (CI) }\end{array}$ & 0.616 & 0.596 & 0.669 & 0.547 & 0.545 & 1.000 & \\
\hline $\begin{array}{l}\text { Records and } \\
\text { Compliance (RC) }\end{array}$ & 0.651 & 0.753 & 0.582 & 0.743 & 0.707 & 0.744 & \\
\hline
\end{tabular}

In order to test the study hypotheses, multiple regressions analysis was used. As mentioned earlier, human resource management (human resource planning, staff development and regulatory compliance, benefits administration, performance appraisal, and recruitment and selection) was treated as a dependent variable and HRIS (strategic integration, forecasting and planning, performance development, human resources analysis, knowledge management, communication and integration, and records and compliance) was treated as an independent variable.

Table 5. Multiple Regression for The Hypotheses

\begin{tabular}{|c|c|c|c|c|c|c|c|}
\hline & R Square & $\mathrm{F}$ & Sig. & Beta & $\mathrm{T}$ & Sig. & Empirical Evidence \\
\hline Strategic Integration & \multirow{7}{*}{0.828} & \multirow{7}{*}{8.874} & \multirow{7}{*}{.000} & .041 & .591 & .556 & Not Supported \\
\hline Forecasting \& Planning & & & & .069 & .661 & .510 & Not Supported \\
\hline Performance Development & & & & .206 & .873 & .005 & Supported \\
\hline Human Resources Analysis & & & & .139 & .223 & .224 & Not Supported \\
\hline Knowledge Management & & & & .436 & .444 & .000 & Supported \\
\hline Communication and Integration & & & & .035 & .448 & .655 & Not Supported \\
\hline Records and Compliance & & & & .168 & .057 & .042 & Supported \\
\hline
\end{tabular}


The above table shows that $F(7,115)=8.874$ and $p$-value $=0.000$. Since the $p$-value is smaller than the level of significance (0.05), the research model is accepted at $p<0.05$ significance level. Hence, there is a statically significant impact of HRIS on HRM. Moreover, as shown above in Table 1, the $\mathrm{R}$ Square's value of (0.828) indicates the proportion of the variance in the criterion variable which is accounted for by the model and shows that about $82 \%$ of the variance in HRM has been significantly explained by HRIS. The fact that HRIS explained more than three quarters of the variance in HRM may be due to the absence of other factor explaining the other half.

The $t$ and sig. (which is known as p-value) values, as shown in Table 1, give a rough indication of the impact of each predictor variable (Kumar, et al, 2010). A big absolute $t$ value and small $\mathrm{p}$ value suggests that a predictor variable is having a large impact on the criterion variable. The results show that performance development, knowledge management, and records and compliance have a significant impact on HRM. Also, the standardized beta coefficient is a measure of the contribution of each predictor or how strongly each predictor variable influences the criterion variable (Kumar, et al, 2010). A large value indicates that a unit change in this predictor variable has a large effect on the criterion variable. The strongest predictor for HRM is knowledge management, achieving a $\beta$ of 0.436 , followed by performance development $\mathrm{t}(\beta=0.206)$, and records \& compliance $(\beta=0.168)$.

The findings revealed that knowledge management is the strongest or the most important predictor of HRM in Jordan. This result is compatible with the fact that knowledge management is considered to be one of the main components of a human resource management system. This was supported by Mayfield and his colleagues who commented, as mentioned earlier, that human resource information systems are mostly created for knowledge management of HRM (2003).

\section{Discussion and Results}

Strategic integration was hypothesized to have a significant relationship with human resource management functionalities. The result of this study found that this hypothesis was not supported. This result does not agree with the fact that human resource management plays an important role in the implementation of corporate strategy within an organization as Markova (2012) commented that "for a long time, HRM has been seen as a key functional area that assures strategy implementation. With the increased importance of HR, HRM is gaining a more prominent role in the strategic decision-making in organizations" (P. 83). This also does not agree with the fact that HRIS plays an important role in the strategic vision of the organization (Rivard et al., 2006). Furthermore, it does not agree with the previous studies carried out by Boateng (2007) and Troshani et al. (2011) who commented that HRIS plays a significant role ensuring that human resources objectives are connected with the organizational overall strategic objectives. Strategy is considered to be a crucial factor in the success of any organization. Not supporting this hypothesis can be argued by the fact that banks in Jordan plan for their strategies but fail to properly implement them (Obeidat, 2008). Nutt (1999) commented that organizations care about formulating their corporate strategies but fail to implement them. Successful implementation can be done by formulating other 
types of strategies which are business and functional strategies. Human resources strategy is considered to be a type of functional strategies which organizations should plan for carefully, however, this study shows that banks in Jordan do not link HRIS presented in strategic integration with their HRM functionalities on one side with their overall corporate strategy, on the other side.

Forecasting and planning was hypothesized to have a significant relationship with Human resources management functionalities. This study did not support this hypothesis and have no relationship between HRM functionalities and forecasting and planning. This means that HRIS does not play a role helping HR department with one of its main roles in the organization which is the creation of human resources future demand on one hand and human resources current and future supply, on the other hand. This result is opposite to what was suggested by Lippert and Swiercz, in 2005 who suggested that HRIS supports strategic planning by creating work force supply and demand needs and requirements. The result of this hypothesis can be argued as banks in Jordan operate in a culture with less future orientation. According to Hofstede (2001), Arab cultures are characterized by focusing on the present rather than the future.

It was also hypothesized that performance development as a dimension of human resources information systems has a significant relationship with human resource functionalities. This study supports this and found that performance development have a relationship with HR functionalities. This agrees with what was discussed Lippert and Swiercz (2005) who commented that HRIS plays a significant role in determining any deficiency an employee has, consequently, managing his/her performance and career development. The result of this hypothesis contradicts with the result of the previous hypothesis that talked about forecasting and planning. It is supposed that whenever an organization plans and forecasts the needs and requirements of their human resources, it helps them in their career plans which is represented in the current hypothesis. This means that banks in Jordan use HRIS in picking up any deficiency an employee has (on the individual level), however, they do not use such information in planning the human resources needs for the whole organization.

It was hypothesized that human resource analysis as a dimension of human resources information system has a significant relationship with human resources functionalities. As it was mentioned earlier, human resource analysis is considered to be an ongoing mean of collecting and identifying human resource needs (Mayfield, et al., 2003). This study did not support this and found no relationship between the two. However, this result is compatible with the result of the second hypothesis concerning the forecasting and planning and does not go with the result of the third hypothesis concerning performance development. The argument of this can be applied on the result of the fourth hypothesis. It can be argued that banks in Jordan use HRIS to analysis the human resources needs of their employees on the individual level (such as training needs) which is congruent with the third hypothesis. Nevertheless, banks do not do this analysis on an organizational level (such as planning the future employees' needs of an organization) which is also compatible with the second hypothesis. 
It was also hypothesized that knowledge management has a significant relationship with human resources management functionalities. This study found that the hypothesis was supported. The results are compatible with what was mentioned earlier in this study about the fact that HRIS are mostly created for knowledge management of HRM (Mayfield et al., 2003). It is argued that without a proper knowledge management that controls the basic data of employees, organizational profitability and effectiveness would be in risk. This can be done as mentioned by Argryis and Schon (1996) and Mayfield, et al. (2003) by facilitating double loop learning feedback that enables organizational change and discussion, intra organizational communication and decision-making and shared visions.

It was hypothesized that communication and integration as a dimension of human resource information system has a significant relationship with human resources functionalities. This study did not support this and found no relationship between the two aspects. As mentioned earlier by Mayfield, et al. (2003), HRIS involves a communication mechanism suitable for communicating necessary information to all customers within and outside an organization. It can be argued that banks in Jordan operate in a culture that is characterized by high power distance (See Hofstede (2001)). According to Hofstede (2001), Arab culture is characterized by having a high power distance in which leaders are expected to resolve disputes as well as make all the difficult decisions without an input from the lower levels of the organization. This was supported by Daniels et al. (2013) who commented that centralization is one of the main elements that characterize such type of culture. Centralization explains the result of having no relationship between the two elements within banks in Jordan.

Finally, the hypothesis of having a significant relationship between record and compliance as dimension of HRIS and HRM functionalities was supported. This result is compatible with the result of the hypothesis of knowledge management since it was suggested by Mayfield and his associates in 2003 that records and compliance function provides very important data for knowledge management. It also agrees with Markova (2012) who commented that HRIS can facilitate organizational actors in tackling questions and challenges as they re-appear in the organization. This means that human resource department uses HRIS as a data base used to protect its activities, accordingly, the organizational ones, consequently, avoid any legal requirements (Decenzo and Robbins, 2011)

\section{Conclusions}

Human resources information systems are considered to be one of the most important elements that affect the activates of human resource department. This was supported by the main hypothesis of this study of having a relationship between human resource information systems and human resources functionalities. However, it was found that some of the dimensions that represent HRIS have a relationship with HRM functionalities and some do not have. It was found that strategic integration, forecasting and planning, human resources analysis, and communication and integration have no relationship with human resource functionalities. Whereas, it was found that performance development, knowledge management, and records and compliance as dimensions of human resources information 
systems have a relationship with human resources functionalities, accordingly, an effect over them.

\section{Implications, limitations, and suggestions}

This study shows the importance of human resource information systems functions in human resources management functionalities. Organizations nowadays operate in an environment that is characterized by being dynamic and of having a hyper competition. In order to face such a tough competition, organizations should invest in their human resources. The results of this study shows that banks in Jordan should care more about their human resources information systems and should benefit more from using it. Banks should make sure that dimensions such as strategic integration, forecasting and planning, human resources analysis, and communication and integration do play a significant role within HR departments. Such factors improve the effectiveness of human resource departments which at the end would have a positive reflection on the organization as a whole.

The results of this study were derived from the data collected in only five banks out of fifteen Jordanian banks. This was because of the fact that most of the banks refused to give access to the researcher to collect data which is considered to be a limitation of this study. Consequently, this study suffers of the generalizability problem which might be overcome if data were collected from more banks. This might also lead to different results. Finally, this study used only a questionnaire as a quantitative method to collect its data. The results of this study could be more valid if other qualitative methods (such as interviews) were used.

\section{References}

Akhtar, S. R., Ding, D. Z., \& Ge, G. L. (2008). Strategic HRM Practices \& their impact on company performance in Chinese enterprises. Human Resource Management, 47(1), 15-32. http://dx.doi.org/10.1002/hrm.20195

Argyris, C., \& Schön, D. (1996). Organizational learning II: Theory, method and practice, Reading, Mass: Addison Wesley.

Ball, K.S. (2001). The use of human resource information systems: a survey. Personnel Review, 30(6), 677-693. http://dx.doi.org/10.1108/EUM0000000005979

Beadles II, N. A., Lower, C. M., \& Johns, K., (2005). The impact of human resource information systems: An exploratory study in the public sector. Communications of the IIMS, $5(4)$.

Beulen, E. (2009). The contribution of a global service provider's Human Resources Information Systems (HRIS) to staff retention in emerging markets Comparing issues \& implications in six developing countries. Information Technology and People, 22(3), 270-288. http:// dx.doi.org/10.1108/09593840910981446

Bowen, D.E., \& Ostroff, C. (2004). Underst\&ing HRM-firm performance linkages: The role of "Strength" of the HRM system. Academy of Management Review, 29, 203-221. http://dx.doi.org/10.2307/20159029 
Bratton, J., \& Gold, J. (2003). Human resource management: Theory and practices (3rd ed.). Pal Grave Macmillan.

Broderick, R., \& Boudreau, J. W. (1992). HRM, IT \& the competitive edge. Academy of Management Executive, 6(2), 7-17.

Casico, W. F. (2006). Managing human resource: Productivity, Quality of work life, Profits ( $7^{\text {th }}$ ed.). McGraw-Hill.

Chadha, S.K., \& Kapoor, D. (2009). Effect of switching cost, service quality \& customer satisfaction on customer loyalty of cellular service providers in Indian market. The Icfai University Journal of Marketing Management, 8(1), 23-37.

Daniels, J., Radebaugh, L., \& Sullivan, D. (2012). International business: Global Edition (14th ed.). Pearson Education.

DeCenzo, D. A., \& Stephen, P. (2010). Fundamentals of human resource management (10th ed.). Wiley High Education.

Dery, K., Grant, D., \& Wiblen, S., (2009). Human resource information systems. replacing or enhancing HRM. Proceedings of the 15th World Congress of the International Industrial Relations Association IIRA 2009, Sydney, Australia, August 27.

Dessler, G. (2013). Human resource management: Global Edition (13th ed.). Pearson Education.

Dessler, G., \& Al Ariss, A. (2012). Human resource management: Arab World Edition. Edinburgh: Pearson Education Limited.

Farndale, E., Hugh, S., \& Paul, S. (2010). The role of the corporate HR function in global talent management. Journal of World Business, 45(2), 161-168. http://dx.doi.org/10.1016/j.jwb.2009.09.012

Florkowski, Gary W., \& Olivas-Luján, Miguel R. (2006). The diffusion of human resource information-technology innovations in U.S. and non U.S. firms, Personnel Review, 35 (6), 684-710. http://dx.doi.org/10.1108/00483480610702737

Gatewood, R. D., Field, H. S., \& Barrick, M. (2008). Human resource selection (6th ed.). South Western: Thomson.

Harris, D. M. \& Desimone, R. L. (1995). Human resource development. TX: Dryden Press, Forth Worth.

Hofstede, G. (2001). Culture's consequences. Thous and Oaks, CA, Sage.

Holincheck, J., Brown, R., \& Woods, J. (2007). Hype cycle for Human Capital Management Software. 2007. Gartner, ID number: G00149590, August 28

Hosie P. (1995). Promoting quality in higher education using human resource information systems. Quality Assurance in Education, 30 1 , 35 http://dx.doi.org/10.1108/09684889510082408 
Hussain, Z., Wallace, J., \& Cornelius, N. E. (2007). The use and impact of human resource information systems on human resource management professionals. Information and Management, 44(1), 74-89. http://dx.doi.org/10.1016/j.im.2006.10.006

Katou, A. A., \& Budhwar, P. S. (2006). Human resource management systems and organizational performance: A test of a mediating model in the Greek manufacturing context. International Journal of Human Resource Management, 17, 1223-1253. http://dx.doi.org/10.1080/09585190600756525

Kossek, E. E., \& Dass, P., DeMarr, B. (1994). The dominant logic of employer-sponsored childcare: human resource managers' institutional role. Human Relations, 47, 1121-1149. http://dx.doi.org/10.1177/001872679404700905

Kovach, K. A., A. A. Hughes, P. Fagan, \& P. G. Maggitti (2002). Administrative \& strategic advantages of HRIS. Employment Relations Today, Summer, 43-48 http://dx.doi.org/10.1002/ert.10039

Kumar, P., Packer, B., \& Koller, D. (2010). Self-Paced Learning for Latent Variable Models. In NIPS.

Lederer, A.L. (1984). Planning and developing a human resource information system. The Personnel Administrator, 29(8), 27-39.

Lepak, D. P., Liao, H., Chung, Y., \& Harden, E. E. (2006) A conceptual review of human resource management systems in strategic human resource management research. Research in Personnel \& Human Resources Management, 25, 217-271. http://dx.doi.org/10.1016/S0742-7301(06)25006-0

Lippers, S. K., \& Swiercz, P. M. (2005). Human resource information systems (HRIS) \& technology trust. Journal of Information Science, 31(5), 340-353. http://dx.doi.org/10.1177/0165551505055399

Markova, G. (2012). Building dynamic capabilities: the case of HRIS. Management Research: The Journal of the Iberoamerican Academy of Management, 10(2), 81-98.

Martinsons, M. (1997). Human resource management applications of knowledge-based systems. International Journal of Information Management, 17(1), 35-53. http://dx.doi.org/10.1016/S0268-4012(96)00041-2

Mathis, R. L., \& Jackson, J. H., (2010). Human resource management. (13th ed.). South-Western College Pub.

Mayfield, M., Mayfield, J., \& Lunce, S. (2003). Human resource information systems: a review \& model development. American Society for Competitiveness, 11(1).

Ngai, E. W. T., \& Wat, F. K. T. (2006). Human resource information systems: a review \& empirical analysis. Personnel Review, 35(3), 297-314. http://dx.doi.org/10.1108/00483480610656702 
Nutt, P. C. (1999). Surprising but true: half the decisions in organizations fail. Academy of management Executive, 1(4), 75-90.

Obeidat, B. Y. (2009). A Study of the implementation Stage of Strategic Decisions in the Banking Sector in Jordan (1st ed.). VDM Verlag Dr. Müller e.K.

Ordóñez de Pablos, P. (2004). A guideline for building the intellectual capital statement: the 3R Model. International Journal of Learning and Intellectual Capital, 1(1), 318. http://dx.doi.org/10.1504/IJLIC.2004.004420

Overman, S. (1992). Reaching for the 21st Century. Human Resource Magazine, 37, 61-63.

Remenyi, D. (2005). 12th European conference on information technology evaluation. Academic Conferences, ISBN: 1-905305-09-5.

Rivard, S., Raymond, L., \& Verreault, D. (2006). Resource-based view \& competitive strategy: an integrated model of the contribution of information technology to firm performance. Journal of Strategic Information Systems, 15, 29-50. http://dx.doi.org/10.1016/j.jsis.2005.06.003

Rodriguez, J. M., \& Ventura, J., (2003). Human resource management systems \& organizational performance: an analysis of the Spanish manufacturing industry. International Journal of Human Resource Management, 14(7), 1206-26. http://dx.doi.org/10.1080/0958519032000114273

Sadri, J., \& Chatterjee, V. (2003). Building organizational character through HRIS. International Journal of Human Resources Development and Management, 3(1), 84-98. http://dx.doi.org/10.1504/IJHRDM.2003.001048

Sekaran, U., \& Bougie, R., (2010). Research Methods for Business A Skill Building Approach (5th ed.). Chichester West Sussex UK John Wiley and Sons

Sheehan, C., \& Cooper, B. K., (2011). HRM outsourcing: the impact of organizational size \& HRM strategic involvement. Personnel Review, 40(6), 742-760. http://dx.doi.org/10.1108/00483481111169661

Shrivastava, S., \& Shaw, J. B. (2004). Liberating HR through technology. Human Resource Management, 42, 201-222. http://dx.doi.org/10.1002/hrm.10081

Tansley, C., Newell, S., \& William, H., (2001). Effecting HRM-style practices through an integrated human resource information system An e-greenfield site?. Personnel Review, 30(3), 351-370. http://dx.doi.org/10.1108/00483480110385870

Troshani, I., Jerram, C., \& Rao, S. (2011). Exploring the public sector adoption of HRIS. Industrial Management and Data Systems, 111(3), 470-488. http://dx.doi.org/10.1108/02635571111118314

Ulrich, D. (1997). Resource Champions. Boston: Harvard University Press. 
Wiblen, S., Dery, K., \& Grant, D. (2010). Transitioning From a Proprietary to Vanilla HRIS: The Resulting Implications for Talent. Proceedings of the 3rd European Academic Workshop on Electronic Human Resource Management, Bamberg, Germany, May 20-21. 